\title{
Pore Characteristics of Vitrain and Durain in Low Rank Coal Area
}

\author{
Dongmin Ma1,2, Qian Li1', Qian He1, Chuantao Wang1 \\ ${ }^{1}$ College of Geology and Environment, Xi'an University of Science and Technology, Xi'an, China \\ ${ }^{2}$ National Energy Key Laboratory of Coal and CBM Simultaneous Extraction, Jincheng, China \\ Email: chant2012@163.com
}

How to cite this paper: Ma, D.M., Li, Q., He, Q. and Wang, C.T. (2017) Pore Characteristics of Vitrain and Durain in Low Rank Coal Area. Journal of Power and Energy Engineering, 5, 10-20.

https://doi.org/10.4236/jpee.2017.511002

Received: September 30, 2017

Accepted: November 17, 2017

Published: November 20, 2017

Copyright (ㅇ 2017 by authors and Scientific Research Publishing Inc. This work is licensed under the Creative Commons Attribution International License (CC BY 4.0).

http://creativecommons.org/licenses/by/4.0/

\begin{abstract}
The low rank coalbed methane (CBM) has great potential for exploration and development in China, but its exploitation level is low at present stage. The pores are the storage space of CBM, so recognizing its structural characteristics has very important practical significance for the development of CBM. The samples of No. 4 and upper No. 4 coalbed in Dafosi were selected to carry out the analysis of mercury injection test, nitrogen adsorption test and scanning electron microscopy to study the different lithotypes of the pore structure, pore throat distribution and fracture character of low rank coal reservoir. The results showed that micropore of low rank coal in Dafosi relatively developed and the pore volume of vitrain was equivalent to durain. The pore throat of durain was larger than vitrain, the connectivity was better and the fissures were more developed. The percolation capacity and reservoir performance of upper No. 4 coal was better than No. 4 coal. Generally, the potential of exploration and development of upper No. 4 coal in the study area was better than that of No. 4, and the developed area of durain was more beneficial for the development of CBM.
\end{abstract}

\section{Keywords}

Low Rank Coal, Vitrain, Durain, Pore Characteristic, Coalbed Methane

\section{Introduction}

The CBM's exploration and development degree of low rank coal area is low in China, only achieving preliminary development in the mining of Xinjiang Fukang, Shaanxi Binchang etc. [1] [2]. In these CBM wells built in Binchang mining area, the maximum daily gas production of the multi-lateral horizontal well 
DFS-C02 in Dafosi mine field has exceeded $3 \times 10^{4} \mathrm{~m}^{3}$, which reflects the exploration and development potential of CBM of low rank coal in Jurassic.

As a storage space for CBM, the pore directly affects the adsorption, accumulation and migration of CBM, and finally affects its output [3] [4] [5]. The pore characteristics of coal reservoir mainly depend on coal macerals and coal rank [6] [7] [8]. Scholars have done a lot of researches on the characteristics of coal pore and its influence on characteristics of CBM gas production. Song X.X. et al. [9] studied pore characteristics of different types of tectonic coals by using small angle X-ray scattering and low temperature nitrogen adsorption experiments. Ma D.M. et al. [10] carried on the contrast research to the powder coal of Shanyang coal field and the original structure coal on pore characteristic. Luo L. et al. [11] discussed the difference of pore structure of lignite and long flame coal in Zhundong. Li M. et al. [12] discussed the influence of minerals on pore structure in tectonic coals. However, few literatures have studied the pore structure characteristics of different lithotypes. Now there is lack of understanding of the microscopic heterogeneity of coal reservoirs, and limited the further development of CBM for low rank coal reservoirs.

In this paper, coal samples were collected from low rank coal in Dafosi mine field. The coal samples of No. 4 vitrain, No. 4 durain and upper No. 4 (the upper coalbed of No. 4) durain in Dafosi were carried out to mercury pressure test, liquid nitrogen test and electron microscope scanning. Then the pore structure, pore type and fracture characteristics of different lithotypes in low rank coal reservoirs were analyzed, which provided the basis for the development of CBM in later stage.

\section{Experimental Samples and Tests}

The experimental samples were collected from No. 4 and upper No. 4 coal seam of Dafosi field in Binchang mining. The coal lithotype included vitrain, clarain, durain and fusain, and the vitrain and clarain were easily recognized by the naked eye. Samples of vitrain and clarain were obtained by hand picking and stripping (Figure 1).

After the coal samples were processed, conventional industrial analysis and helium porosity were carried out. Moreover, Auto Pore9505 mercury porosimetry, ASAP2020 specific surface tester and EVO-MA15 scanning electron microscope were used for the mercury injection test, liquid nitrogen test and scanning electron microscope observation.

\subsection{Industrial Analysis}

The serial number of each sample and the results of industrial analysis were shown in Table 1. Overall, the vitrain's moisture content was higher than durain, but the ash productivity and fixed carbon content were lower than durain. The moisture content, ash and volatile productivity and fixed carbon content of upper No. 4 durain were equivalent to those of No. 4 durain. 

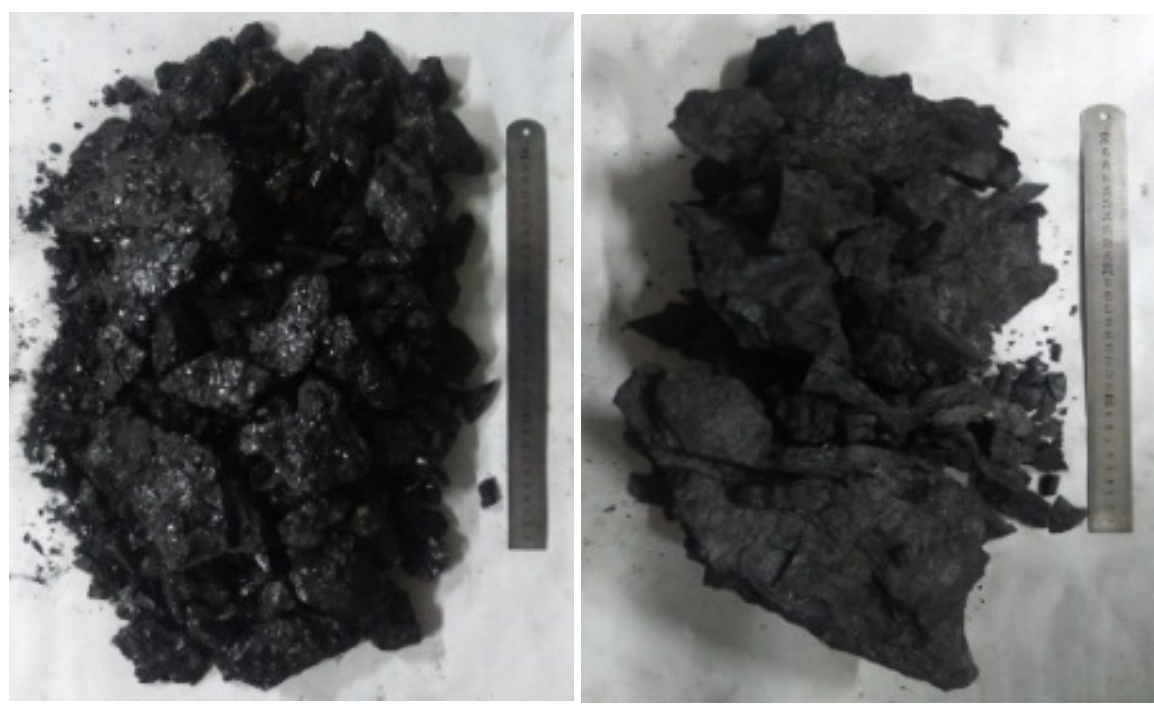

Figure 1. Vitrain (left) and durain (right).

Table 1. Industrial analysis results of samples.

\begin{tabular}{ccccc}
\hline Samples & $M_{\mathrm{ad}} / \%$ & $A_{\mathrm{ad}} / \%$ & $V_{\mathrm{dad}} / \%$ & $F C_{\mathrm{ad}} / \%$ \\
\hline No. 4 vitrain & 6.06 & 9.40 & 36.57 & 53.62 \\
No. 4 durain & 4.32 & 14.04 & 26.73 & 59.82 \\
Upper No. 4 durain & 5.25 & 13.02 & 26.84 & 59.79 \\
\hline
\end{tabular}

\subsection{Porosity}

The method of helium porosity was used for the determination of porosity $(\varphi)$. The principle is as follows. With a known volume of standard body, the gas makes an isothermal expansion at an atmospheric pressure of the coal sample at the initial set pressure. When the gas diffuses into the pores of the coal sample, the effective pore volume and particle volume of the measured coal sample can be calculated, and the porosity of coal sample can be calculated according to gas equation. The experimental results showed that the porosity of the No. 4 coal vitrain was $4.9 \%$, greater than $3.9 \%$ of the durain, which might be the reason that the density $(\rho)$ of the durain $\left(1.48 \mathrm{~g} / \mathrm{cm}^{3}\right)$ was greater than that of vitrain $(1.19$ $\mathrm{g} / \mathrm{cm}^{3}$ ). When Jin X.L. et al. [13] and Zou H.J. [14] studied the characteristics of Erdos's low rank coal pore, they measured the porosity of No. 4 coal in Dafosi was $15.0 \%$ and $10.9 \%$, were higher than $4.9 \%$. It might be affected by the micro cracks of different position in coal samples, which needed further experiments to prove.

\section{Mercury Pressure Test and Analysis}

Mercury intrusion test was an indirect experimental method for pore volume, aperture and its distribution [15] [16]. Mercury does not damp on the general solid. In order to make mercury enter the hole, it is necessary to exert external pressure. The greater the external pressure is, the smaller the radius of the hole 
that mercury can enter. The amount of mercury entering the hole under different external pressures is measured to determine the pore size of the corresponding hole. In this paper, the pore structure parameters of coal reservoir were analyzed by 8 means of throat mean value $(r)$, median radius $\left(r_{50}\right)$, sorting $\left(S_{\mathrm{p}}\right)$, skewness $\left(S_{\mathrm{k}}\right)$, kurtosis $\left(K_{\mathrm{g}}\right)$, displacement pressure $\left(P_{\mathrm{d}}\right)$, median pressure $\left(P_{50}\right)$ and efficiency of mercury withdrawal $\left(W_{\mathrm{E}}\right)$. Combined with porosity and density characteristics, the pore structure characteristics of vitrain and durain of low rank coal were analyzed. The test results of each parameter were shown in Table 2.

\subsection{Hole Throat Size}

The pore throat size was mainly characterized by mean and median radius of throat. The mercury injection of 3 samples showed that, for No. 4 coal, the pore throat of the durain was larger than that of the vitrain, which was beneficial to the migration of gas molecules. The average pore throat size of No. 4 coal was as same as upper No. 4 coal. The mean radius of pore throat showed the central value of the normal distribution of pore throat radius. The median throat radius was the highest, and the radius of throat radius decreased at both sides. In addition, the pore throat median radius of durain was larger than that of the vitrain in No. 4 coal by experiment. The results showed that the pore throat of the durain was larger than that of the vitrain in general. Similarly, the test results showed that the gap throat of upper No. 4 durain was larger than of No. 4 coal.

\subsection{Hole Throat Distribution}

The sorting coefficient can directly reflect the concentration or uniform degree of pore throat distribution, and is a measure of the standard deviation of pore throat size. The throat sorting coefficient of vitrain and durain of No. 4 coal sample was more than 3.0. The poor sorting quality also showed that the coal reservoir permeability of the sample was bad. Sorting coefficient of durain was smaller than that of vitrain, which indicated durain's sorting was slightly better. Through the pore throats were distributed in different pore sizes and mesopore number was far greater than vitrain, pore throat was still concentrated in micropores and small pore segments (Figure 2). The skewness was the symmetry parameter of the throat frequency distribution, which reflected whether the throat distribution was large or small relative to the mean. The test results showed that the distribution of the pore throat of vitrain was positive skewness,

Table 2. Mercury test results of vitrain and durain in Dafosi.

\begin{tabular}{ccccccccc}
\hline Samples & $r / \mu \mathrm{m}$ & $r_{50} / \mu \mathrm{m}$ & $S_{\mathrm{p}}$ & $S_{\mathrm{k}}$ & $K_{\mathrm{g}}$ & $P_{\mathrm{d}} / \mathrm{MPa}$ & $P_{50} / \mathrm{MPa}$ & $W_{\mathrm{E}} / \%$ \\
\hline No. 4 vitrain & 3.18 & 0.01 & 4.98 & 1.42 & - & 0.03 & 93.03 & 63.88 \\
No. 4 durain & 4.83 & 0.02 & 3.39 & -1.37 & - & 0.02 & 44.42 & 36.56 \\
Upper No. 4 durain & 4.90 & 0.05 & - & -1.03 & 4.66 & 0.02 & 14.34 & 42.45 \\
\hline
\end{tabular}

“_" indicated that data was not tested. 


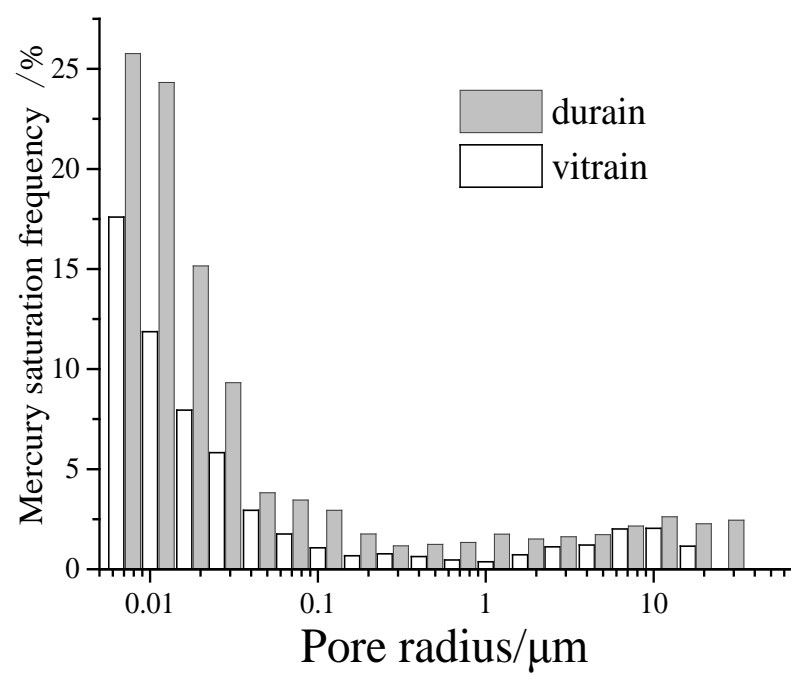

Figure 2. Mercury saturation and pore size distribution.

and the throat intruded by mercury was in a larger throat state. The distribution of the durain's pore throat was negatively skewed, and the throat was in a small throat state. Besides, the pore throat of durain of upper No. 4 was larger than that of No. 4. The kurtosis of pore throat reflected the ratio of two tail stenter in the distribution of amplitude. This experiment measured only the kurtosis of upper No. 4 coal. The larger numerical value indicated that the pore throat distribution of different sizes was relatively dispersed in the coal reservoir of upper No. 4 coal.

\subsection{Hole Throat Seepage Capacity}

The seepage capacity of pore throat can be described by the mean and median radius of the pore throat, in addition to displacement pressure and median pressure. The displacement pressure Pd refered to the capillary pressure corresponding to the largest connected pore throat in the pore system. The smaller the driving pressure was, the bigger the pore throat was connected, and the better the connectivity and the seepage capacity of the pore throat would be. The experimental results showed that the displacement pressure of durain was smaller than vitrain in No. 4 coal, and its seepage ability was relatively better. It was conducive to the migration of gas molecules consistent with throat radius test results; the durain's displacement pressure of upper No. 4 coal was bigger than No. 4 coal, which showed upper No. 4 coal had better seepage ability. Mean pressure was the corresponding capillary pressure when mercury saturation was $50 \%$. It was a measure of the trend of capillary pressure distribution. The greater the median pressure was, the more compact the sample was and the poorer the ability to store gas would be. The mean pressure of durain of No. 4 coal was smaller than that of vitrain, which was more conducive to the storage of CBM. So the storage capacity of upper No. 4 coal was better than that of No. 4 .

\subsection{Hole Laryngeal Connectivity}

By the analysis of curve shape of Figure 3, the mercury injection saturation of 


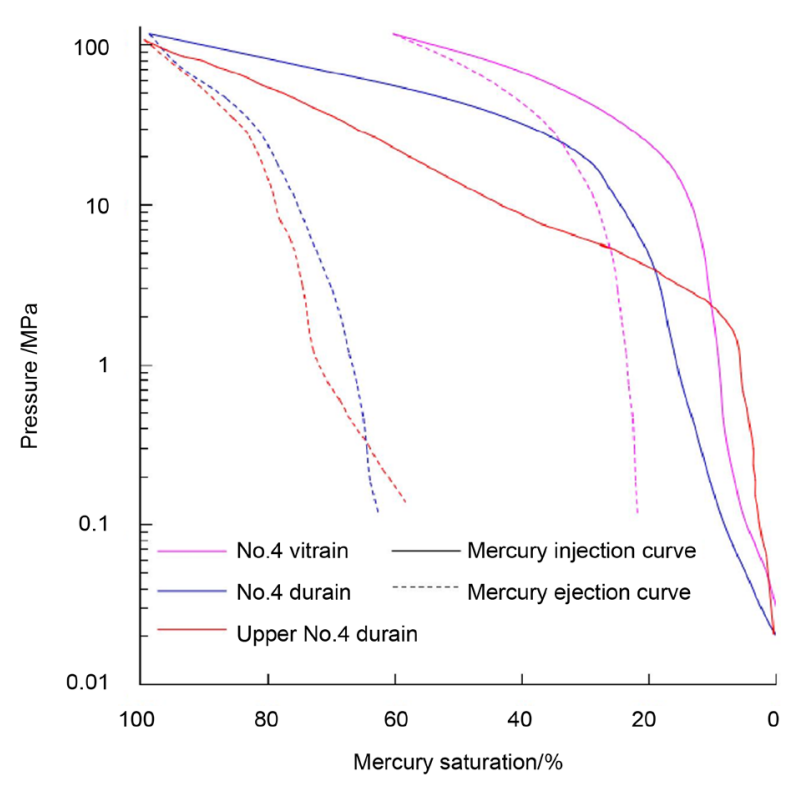

Figure 3. Mercury Pressure curves of each sample.

durain was much larger than the vitrinite $(60.20 \%)$, which was close to $100 \%$. It showed that the connectivity of the pore throat of durain was excellent and almost all pores were occupied by mercury; the mercury injection saturation of vitrain was small and the pore volume not occupied by mercury was larger, so the whole pore connectivity of vitrain was poor. Mercury injection curves of three kinds of coal samples showed hysteresis in different degrees. The efficiency of mercury ejection withdrawal of vitrain (63.88\%) was higher than durain (No. 4 durain was $36.56 \%$ and upper No. 4 durain was $42.45 \%$ ). The reason was that the pressed mercury could exit effectively because of thick pore throat, in spite the overall coal pore connectivity of vitrain was poor. It was consistent with the results shown by the deflection of the hole throat. Compared with durain of No. 4 coal, the pore connectivity of upper No. 4 durain was better. The mercury injection curve of No. 4 durain had longer straight section and smaller slope. It showed that the throat distribution of upper No. 4 durain was smaller than that of No. 4, which was consist with the results of pore throat skewness and kurtosis analysis.

\section{Liquid Nitrogen Adsorption Test Analysis}

\subsection{Pore Volume and Specific Surface Area}

Pore volume ( $V$ ): The experiment of liquid nitrogen adsorption (Table 3) showed that, in the durain and vitrain of No. 4 coal, microporous $\left(V_{\mathrm{mi}}\right)$ was accounted for $50 \%$ of the total pore volume, small hole $\left(V_{\mathrm{s}}\right)$ occupied more than $1 / 3$ of the total pore volume, mesopore $\left(V_{\mathrm{me}}\right)$ occupied a smaller proportion and macropore $\left(V_{\mathrm{ma}}\right)$ volume could not be measured; however, in the upper No. 4 durain, the pores were distributed in each pore section and small holes accounted for nearly $60 \%$ of the total pore volume, which might be related to the 
Table 3. Test results of liquid nitrogen adsorption.

\begin{tabular}{ccccccccccc}
\hline Sample & $V / \mathrm{mL} \cdot \mathrm{g}^{-1}$ & $V_{\mathrm{mi}} / \%$ & $V_{\mathrm{s}} / \%$ & $V_{\mathrm{me}} / \%$ & $V_{\mathrm{ma}} / \%$ & $S / \mathrm{m}^{2} \cdot \mathrm{g}^{-1}$ & $V_{\mathrm{mi}} / \%$ & $V_{\mathrm{s}} / \%$ & $V_{\mathrm{me}} / \%$ & $V_{\mathrm{ma}} / \%$ \\
\hline $\begin{array}{c}\text { No. } 4 \text { vitrain } \\
\text { No. 4 durain }\end{array}$ & 0.01894 & 50.11 & 36.69 & 13.20 & - & 13.1979 & 90.27 & 9.22 & 0.51 & - \\
$\begin{array}{c}\text { Upper No. } 4 \\
\text { durain }\end{array}$ & 0.01676 & 50.00 & 35.68 & 14.32 & - & 11.5236 & 90.74 & 8.61 & 0.65 & - \\
\hline
\end{tabular}

coal seam depth and coal accumulation environment. The total pore volume of vitrain was equivalent to durain in No. 4 coal and upper No. 4 durain was bigger than that of No. 4 , which indicated that upper No. 4 durain was more favorable to the storage of CBM, consistent with the mercury pressure test analysis.

Specific surface area $(S)$ : The distribution of specific surface area of the sample was consist with pore volume distribution. The micropore of No. 4 coal accounted for more than $90 \%$ of the surface area, which contributed largest for specific surface area. Small pore surface area accounted for less than $10 \%$. For upper No. 4 durain, the contribution of micropores and pores to the specific surface area was about $50 \%$. As for the total specific surface area, vitrain was equivalent to No. 4 durain and upper No. 4 durain was larger than that of No. 4 , indicating that upper No. 4 durain had better adsorption capacity.

\subsection{Adsorption/Desorption Curve Analysis}

The adsorption and desorption curves of liquid nitrogen adsorption method can also be applied to the pore morphology analysis of coal. The loop formed by the separation of adsorption curve and desorption curve is called adsorption hysteresis loop. The shape and position of hysteresis loop can reflect the morphological characteristics of the pore [17] [18].

In Figure 4, the adsorption curves of three kinds of coal samples belonged to the II curve in the BET classification scheme. When the relative pressure $\mathrm{P} / \mathrm{P}_{0}$ was less than 0.1 , the adsorption curve had a sharp rise in the process. This was due to the capillary filling of the nitrogen molecule in the micropores and the adsorption of the monolayer on the larger pore wall. When the relative pressure $\mathrm{P} / \mathrm{P}_{0}$ was at $0.1 \sim 0.8$, the curve rose slowly and this stage was a multi-molecular layer adsorption process on the larger pore wall. When the relative pressure $\mathrm{P} / \mathrm{P}_{0}$ was more than 0.8 , the adsorption curve began to rise sharply. This was due to the capillary condensation of nitrogen molecules in the mesopores and macropores.

The liquid nitrogen absorption/desorption curves of vitrain and durain of No. 4 were similar. As the relative pressure decreased, the desorption curve decreased slowly, and the hysteresis loop was formed due to the simultaneous existence of the open hole and the half closed cell. When the relative pressure dropped to 0.5 (the corresponding aperture was about $4 \mathrm{~nm}$ ), the condensation of the "ink bottle" hole was about to evaporate. If the pressure decreased slightly, the liquid would be poured out, showing a sharp decline in the curve. When the 


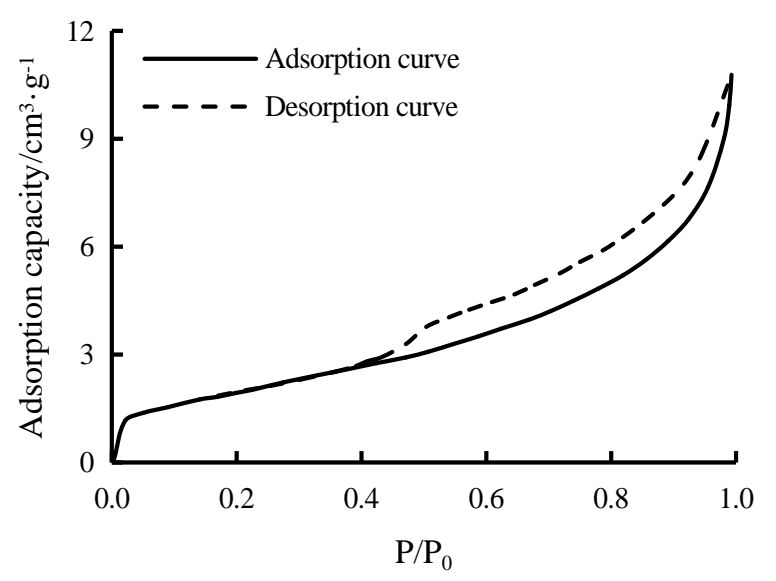

(a)

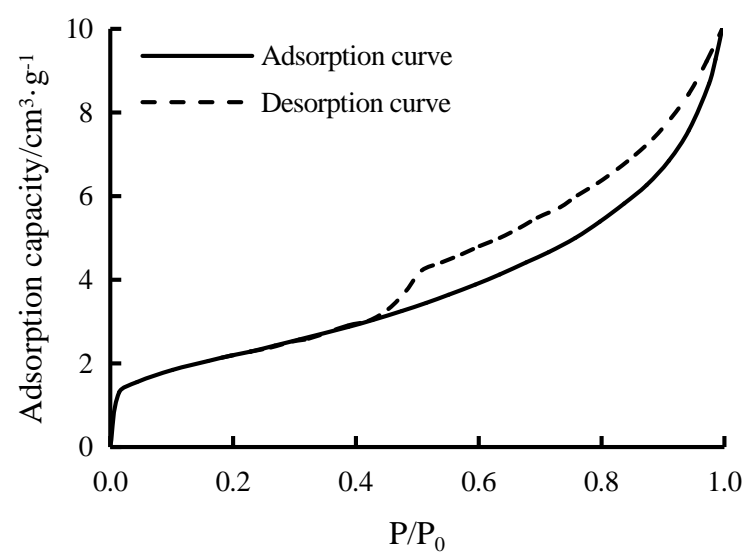

(b)

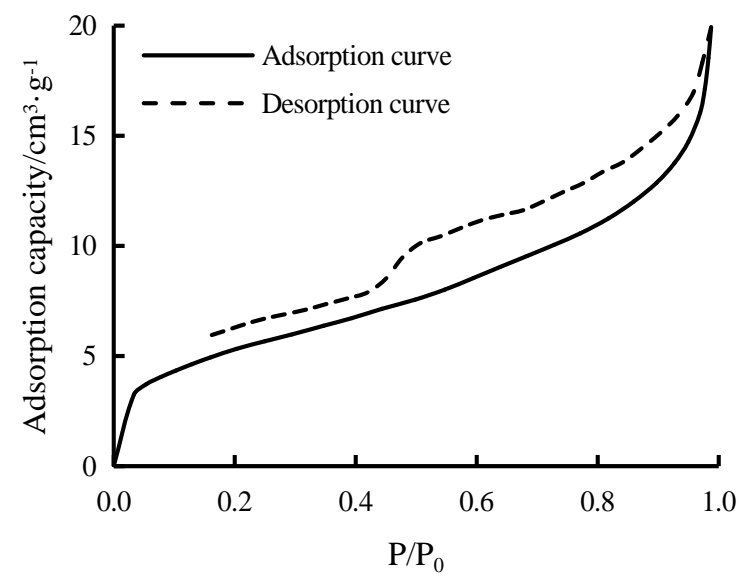

(c)

Figure 4. Test curves of liquid nitrogen adsorption for each sample. (a) No. 4 vitrain; (b) No. 4 durain; (c) upper No. 4 durain.

relative pressure was less than 0.5 , there was only half closed hole in the corresponding pore section, and the desorption curve coincided with the adsorption curve basically. In addition, when the relative pressure was more than 0.5 , the adsorption/desorption curves of upper No. 4 durain was similar to that of No. 4 
durain. The difference was that the open hole and half closed hole existed at the same time when the pore size of upper No. 4 durain was less than $4 \mathrm{~nm}$. When the relative pressure was greater than 0.5 , there was hysteresis.

\section{Scanning Electron Microscopy Analysis}

The scanning electron microscope test results can reflect more than $0.1 \mathrm{~nm}$ of the hole and fissure development, coal surface features, microstructure and mineral composition and other information [19] [20]. The scanning results were shown in Figure 5.
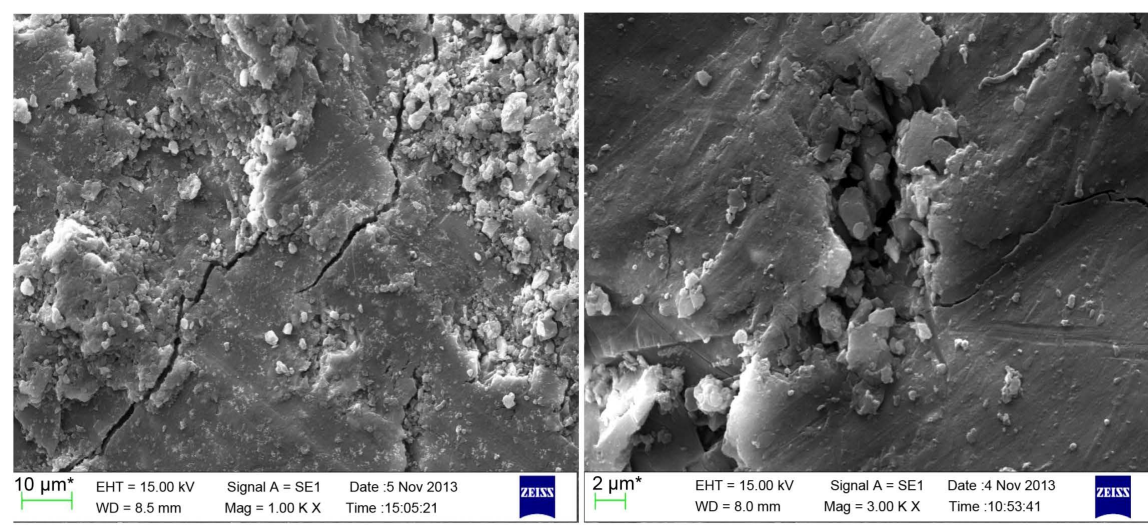

(a)
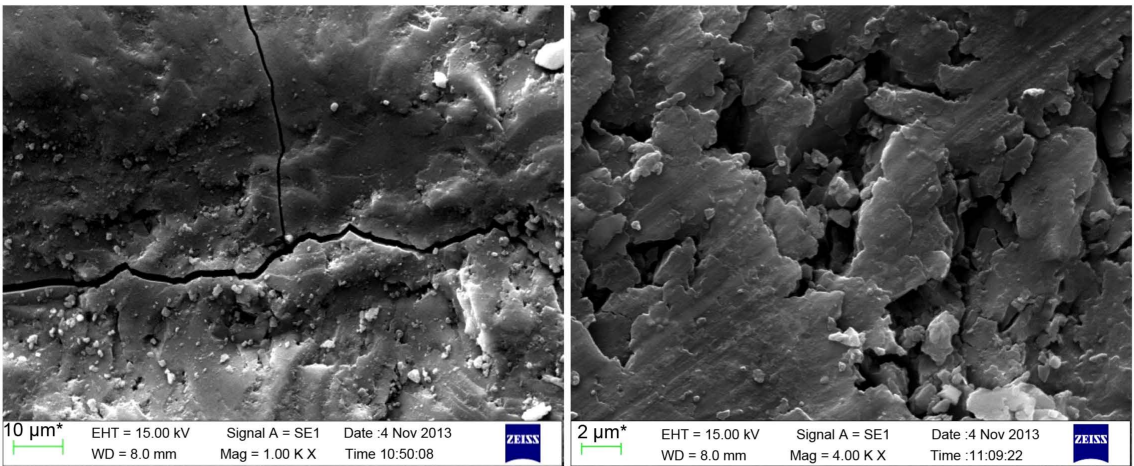

(b)
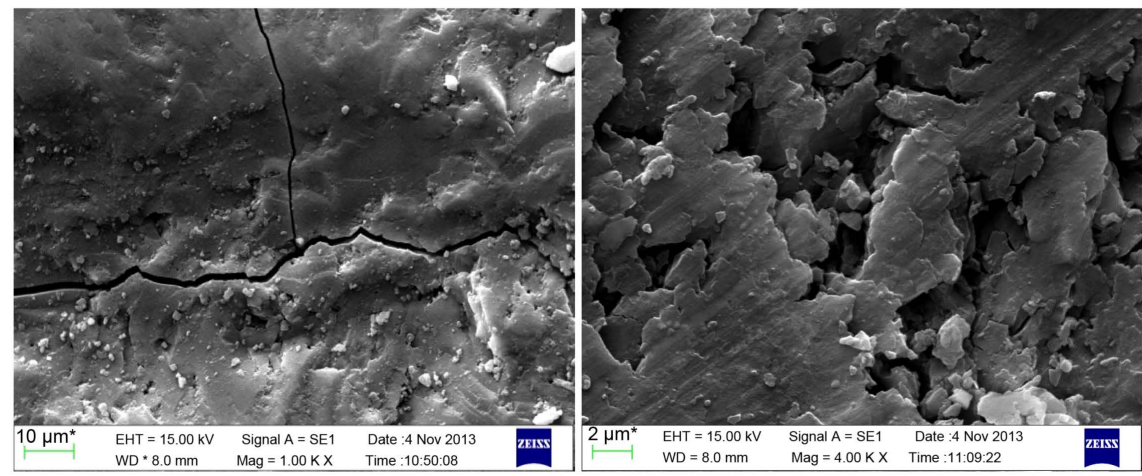

(c)

Figure 5. Scanning electron microscopy analysis of coal samples. (a) No. 4 vitrain; (b) No. 4 durain; (c) upper No. 4 durain. 
In Figure 5, the debris on the surface of No. 4 vitrain was plenty and porosity was not developed. Restricted by the debris, it was possible the inter hole connection happened only partial of coal surface. The surface of No. 4 durain was smoother than upper No. 4 vitrain. The debris of surface formed micropores and the pore's connectivity was better than No. 4 vitrain. Moreover, the visible width of crack was about $1-2 \mu \mathrm{m}$. The surface of upper No. 4 durain was smooth and pores developed well. The connectivity was good and the visible width was about $1-2 \mu \mathrm{m}$. The angle between the fissure and the fissure was nearly 90 degrees.

\section{The Significance of Pore Characteristics for CBM Exploration and Development}

The pore structure, type and distribution were the important parameters of coal reservoir. The difference of the pore system, coal formation environment, metamorphism and late tectonism were closely linked, therefore resulting in the coal reservoir had a strong heterogeneity. For the exploration and development of CBM, favorable reservoirs and unfavorable reservoirs were formed naturally. The study of the pores in the coals of different lithotypes was helpful to the understanding of the properties of the coal reservoirs and the evaluation of the reservoir properties, so as to guide the exploration, selection and development of $\mathrm{CBM}$ in the later period.

\section{Conclusions}

1) In the No. 4 coal seam of Dafosi, the micropore of vitrain developed better. The pores of durain were distributed in each pore section, and the pores were dominated by micropores. The pore volume and the specific surface area of vitrain was equipment to durain. Compared with vitrain, the durain had larger pore throat, better connectivity, more developed fracture and better percolation capacity and reservoir performance.

2) For different coal seams, the porosity, pore volume and specific surface area of upper No. 4 were more developed than that of No. 4 . The pores of upper No. 4 were distributed in each pore section, and the pores were dominated by micropores. The pore throat was large; the fissure developed vertically in two directions, and the pore connectivity was good. The percolation capacity and reservoir performance of the upper No. 4 were better than that of No. 4.

3) For Dafosi field, the upper No. 4 was more favorable for the exploration and development of CBM. For the different of lithotype of low rank coal, the development of CBM may be more favorable for the areas where the durain is more developed.

\section{References}

[1] Wang, J.T. (2016) Block Division and Potential Evaluation of Coal-Bed Methane Development in Fukang Mining Area. Henan Polytechnic University, Jiaozuo.

[2] Xin, X., Zhang, P.H., Jiang, Z.B., et al. (2014) CBM Reservoir Parameters and Exploitation Potential in Binchang Mining Area. Coal Geology of China, 3, 19-22. 
[3] Liu, A.H., Fu, X.H., Liang, W.Q., et al. (2013) PORE Distribution Features of Different Rank Coal and Influences to Coal Bed Methane Development. Coal Science and Technology, 41, 104-108.

[4] Yang, G.F. (2013) An Research on the Physical Properties of Different Rank Coal Reservoirs. Anhui University of Science and Technology, Huainan.

[5] Li, Z.W., Lin, B.Q., Hao, Z.Y., et al. (2013) Characteristics of Pore Size Distribution of Coal and Its Impacts on Gas Adsorption. Journal of China University of Mining \& Technology, 42, 1047-1053.

[6] Wang, S.W., Chen, Z.H., Zhang, M., et al. (2003) Application of the Technique of Coal Facies Analysis to Evaluation of Coal Reservoir. Geological Journal of China Universities, 9, 396-401.

[7] Wang, C.X. and Li, S.G. (2015) Pore Structure Characteristics of Low Rank Coal and Their Influence on Gas Adsorption. China Safety Science Journal, 25, 133-138.

[8] Li, Z.W. (2015) Study on Microstructure Characteristics of Low Rank Coal and Its Control Mechanism on Gas Adsorption/Desorption. China University of Mining and Technology, Beijing.

[9] Song, X.X., Tang, Y.G., Li, W., et al. (2014) Pore Structure in Tectonically Deformed Coals by Small Angle X-Ray Sacttering. Journal of China Coal Society, 39, 719-724.

[10] Ma, D.M., Liu, H.N., Li, P., et al. (2015) Comparison Study of Shanyang Mine Field Pulverized Coal and Undeformed Coal Pore Properties. Coal Technology, 34, 68-70.

[11] Luo, L., Tang, D., Tao, S., et al. (2016) Pore Structure and Its Influence on Gas Mass Transfer of Low Rank Coal in Eastern Junggar Basin in Xinjiang. Journal of China Coal Society, 41, 941-947.

[12] Li, M., Jiang, B., Qin, Y., et al. (2017) Analysis of Mineral Effect on Coal Pore Structure of Tectonically Deformed Coal. Journal of China Coal Society, 42, 726-731.

[13] Jin, X., Zhang, P. and Wu, M. (2012) Pore Features and Geological Significance of Low Rank Coal Reservoirs in Erdos Basin. Coal Science and Technology, 40, 22-26.

[14] Zou, H. (2013) The Admissibility Study of Coal Bed Methane in Dafosi Area. Chang'an University, Xi'An.

[15] Zhang, N., Qiao, F., Zhang, B., et al. (2016) Experimental Study on Pore Structure Features of Sedimentary Rocks in Deep Coal Measures by Mercury Intrusion Porosimetry. Coal Science and Technology, 44, 155-160.

[16] Zhang, T., Wang, X., Li, S., et al. (2016) Study on Influencing Factors in Determining Pore Characteristics of Shale by Mercury Intrusion. Rock and Mineral Analysis, 35, 178-185.

[17] Budaeva, A.D. and Zoltoev, E.V. (2010) Porous Structure and Sorption Properties of Nitrogen-Containing Activated Carbon. Fuel, 89, 2623-2627.

[18] Lin, Y., Jia, X., Ma, D., et al. (2016) Study and Application of Coal Pore Features Based on Liquid Nitrogen Adsorption Method. Coal Science and Technology, 44, 135-140.

[19] Li, X. and Cao, D. (2012) The Structural Evolution Character of Different Types of Coal Metamorphism and Its Geological Significance. Journal of China University of Mining \& Technology, 41, 74-81.

[20] Lee, G.J., Pyun, S.I. and Rhee, C.K. (2006) Characterisation of Geometric and Structural Properties of Pore Surfaces of Reactivated Microporous Carbons Based upon Image Analysis and Gas Adsorption. Microporous \& Mesoporous Materials, 93, 217-225. 